\title{
Ambivalent Professionalisation and Autonomy in Workers' Collective Projects: The Cases of Sex Worker Peer Educators in Germany and Sexual Assistants in Switzerland
}

\author{
by Giulia Garofalo Geymonat and P.G. Macioti \\ Lund University; International Committee on the Rights of Sex Workers in Europe
}

Sociological Research Online, 21 (4), 10

<http://www.socresonline.org.uk/21/4/10.html>

DOI: $10.5153 /$ sro.4146

Received: 16 Aug 2016 | Accepted: 27 Oct 2016 | Published: 30 Nov 2016

\begin{abstract}
Drawing on participant methodologies this article examines two cases of workers' self-organised projects oriented to improving the quality of sex work and to 'professionalisation'. The first case is a group of sexual assistants for people with disabilities, who have organised meetings and training for sexual assistants in a medium-sized city in Switzerland. The second is a group of peer sex worker educators offering workshops to people who sell sex in various industry sectors in a large German city. We argue that these activist interventions may represent a resource for identifying crucial aspects of work-quality and professionalisation in sex work and for making sense of some apparent contradictions of sex workers' organising. Indeed, through ongoing conversations and recommendations about working practices and ethics, our participants develop situated views of what is better sex work and they originally engage with key conceptual areas, such as consent, autonomy, standardisation, income and professional identity. They do so by comparing a variety of experiences in sex industries, as well as discussing similarities with other jobs such as body work, care work, and psychotherapy.
\end{abstract}

Keywords: Sex Work, Sexual Assistance, Sex Workers Organisations, Germany, Switzerland, Quality of Work

\section{Introduction}

In the last decade the movement for sex workers' rights has mounted an increasing number of initiatives, gaining global visibility. Correspondingly, a body of research has emerged analysing sex workers' organising efforts and the knowledge produced among activists. A number of recent large consultation and participatory projects including sex workers' groups - among others Mai (2009) and Amnesty International (2016) - have documented the centrality of structural inequalities, discrimination, stigma, migration status, and criminalisation in the working lives of people who find themselves in the position of selling sex. These are all issues that have been addressed in several documents of the sex workers' movement since its outset (Pheterson ed. 1989; Kempadoo \& Doezema eds. 1998; Macioti 2014; Garofalo Geymonat \& Macioti eds. 2016; ICRSE 2016). Moreover, researchers have looked at sex workers' organisations, their political alliances and forms of unionisation, as well as their impact on policy change (West 2000; Mathieu 2003; Gall 2007; Garofalo 2010; Andrijasevic et al. 2012; Majic 2013; Garofalo Geymonat 2016; Jackson 2016). Some found that sex workers' struggles to reduce exploitation are similar to those we find with respect to other forms of reproductive work, such as domestic and care work or other forms of intimate and affective labour (Ditmore 2007; Cobble 2010; Hardy 2016). For instance, sex workers are concerned by fines for bogus infractions at work, being compelled to do unpaid overtime, bullying by managers, and being forced to work long hours without breaks, as well as by the quality of the relationship with their clients, and the high risk of burn-out (Sanders 2004; Vanwesenbeeck 2005; Gall 2006; Sanders \& Hardy 2014). Similarly to other forms of reproductive labour, and increasingly other forms including cognitive and affective labour (Hardt 1999, Negri \& Hardt 1999, Morini 2007), for sex workers the means of production essentially consist of their very bodies and selves, rather than the forms of accumulated capital typical of industrial production. This represents both an opportunity for 
unusual spaces of workers' autonomy from capital and the state, and simultaneously a limit to the

possibilities for worker organising. Indeed, in the contemporary European context, a growing precarious and 'feminised' labour force is increasingly characterised by dynamics of strategic individualism, self-

disciplining, and immediate competition between (the bodies of) workers and groups of workers (Morini 2007). In addition to these elements, sex work remains highly stigmatised if not illegal in contemporary Europe, and a large part of the labour force is constituted by migrants without papers, which calls for specific forms of organising, and thinking, resistance and quality of work and life (Caradonna interviewed in Brekke 2008).

1.2 In this scenario, little attention has been paid to what might, at least provisionally, be called the 'professionalising' side of the sex workers' movement. By this we mean all those projects that proactively elaborate and spread better working practices in the sex industry, and in particular those that do so through direct actions of knowledge-sharing put into place by sex workers for other sex workers. These kinds of self-organised initiatives have become more visible in the last decade in a number of European countries, such as Spain, France, Britain, Germany, and Switzerland. Often - if not always - they start off from pre-existing sex workers' organisations and then develop independently. Such is the case of the x:talk project in Britain, a sex worker-led workers' cooperative providing English classes and other training to sex workers in London. X:talk exists autonomously of the International Union of Sex Workers, from which it developed in 2004. Other projects range from two-hour workshops on how to use BDSM professionally through how to deal with stigma, clients, managers, or taxes, to one-day workshops on how to decide if sex work is for you and how to do it. These kinds of projects have been multiplying, often offered for free, sometimes for a fee, and mostly with little or no public or charity funds. The reasons for these developments in contemporary Europe deserve separate exploration. In particular, it would be interesting to see whether they can be connected to the accelerated erosion of informal space for knowledge-transmission over the last twenty years, possibly related to the increased precariousness of working conditions in the industry, greater mobility, and the radical fragmentation of the sex work labour force, divided into numerous different ethnic and national groups, often speaking different languages (Agustin 2007; Tampep 2009; Andrijasevic 2013; Cruz 2013). The relatively recent development of collective workers' knowledge may on the other hand also be related to the long-term consequences of laws that have either directly or indirectly criminalised sex workers or discouraged sex workers from working together and from exchanging information about work. Indeed, these are all activities that may be criminalised as 'pimping' or 'facilitating' prostitution or trafficking (Crowhurst et al. 2012; Pitcher \& Wijers 2014).

1.3 In such a context, we think these self-organised groups may represent a source of innovative knowledge on the quality of work in sex work, especially when a participant methodology is applied. In fact, participation is a requirement even of being able to access these projects, which otherwise remain closed to researchers. Moreover, participation in the collective process is crucial in order to give justice to the particular knowledge produced within these projects, and develop a position of ethical accountability vis-à-vis the collectives. Indeed, when they gather away from abolitionist and prohibition pressures, sex workers and sexual assistants appear to produce a very original understanding of their activities, slightly different from the various versions of 'sex work is just like any other job' that they may prefer to present in public. Within protected collectives, sex workers and sexual assistants may feel less pushed to defend their work and 'look happy about it' (Caradonna 2016), and may take the time to talk through the particular mobilisation of the self and the body involved in sex work and sexual assistance, address the particular forms that exploitation may take therein, and even cultivate their collective imagination around what sex work and sexual assistance could, or should, look like in a better world.

1.4 We choose to call these 'professionalising' projects, because they appear to propose forms of collective guidelines elaborated by sex workers as a category of workers, in a way that builds on and develops their professionality and suggests how sex work functions as - and can be understood as - a profession. However, we will place inverted commas around the expression 'professionalising', since, as we will show, other aspects traditionally connected to professionalisation are very contested within the groups we studied. Indeed, in the paper we argue that sex workers' self-organised 'professionalising' today in Europe may interrogate the ways in which professionalisation, quality of work, and workers' organising are understood as being linked to the monopoly on specialised knowledge, control of entry into the occupation, the building of a professional identity, as well as standard working rules, collectively negotiated contracts, and full-time employment as an ideal (Witz 1990; Gall 2006; Muñoz de Bustillo et al. 2012). 
sex work', i.e. a good quality of sex work. It is interesting to see how across very different contexts in the industry, our participants engage in similar ways with two conceptual areas, namely autonomy and consent. These are crucial to the debate on sex work, and work at large. Partly in response to laws and public discourse that tend to denigrate sex workers - who are seen as 'selling out' their autonomy - and to rigidly separate them into those who are always already unable to consent (the 'real victims') and the others (the 'real whores'), the work of our collectives points to a view of good working (and living) conditions that puts at the centre autonomy and consent as processes that are never accomplished and always need to be struggled for. Furthermore, our participants associate good working (and living) conditions with other areas of the debate on the quality of work: working rules or standards, income, and (professional) identity. However, while these areas are usually associated with security at work and success as a professional, our participants treat them with extreme caution, as if they were 'traps' to be avoided when working as sex workers or sexual assistants.

\section{Methodology}

The present article stems from a collaborative project on the quality of work in the sex industry, which the authors began in 2015. The materials used herein have been collected within the framework of other research projects each of us has been conducting with the organisations under study. We both use ethnography, in other words embedded participant observation, as our research method. Ethnography is a particularly productive method in the study of social movements (Plows 2008), for 'the essence of this approach is to view events through the perspective of the people being studied' (Bouma \& Atkinson 1995: 207), and because it allows participants to frame issues on their own terms. This is particularly relevant for a social sphere such as the sex industry, dominated by an ideology which positions prostitution as completely different from other forms of labour or sex, and that does not recognise sex workers as experts in their own experiences, whether negative or positive.

Self-organised, 'professionalising' projects in contemporary Europe are often sex-worker only spaces, open only to close allies. Indeed, to do participant observation with Sophie and BodyUnity was only possible because we are both activists in this field, and have been for the past fifteen years in different contexts in Europe. We have both been immersed in our fields and in their activist practices for the last three years. In particular, PG Macioti has worked for the organisation that hosts the SOPHIE project and participated in a large number of workshops (about 40 per cent), and organisational and skills development meetings and training sessions (about 80 per cent) over the span of three years (around 250 hours). Giulia Garofalo Geymonat was able to participate in all the training sessions arranged by the organisation BodyUnity over the span of one and a half years (a total of 150 hours) and conducted formal complementary interviews with the course trainers and key members. We both regularly took notes following the numerous face-to-face informal meetings with participants, and we have translated into English the quotes included in the article.

As activist researchers we each occupy an uneasy space that challenges the insider/outsider division that has attracted the attention of feminist scholarship (Maxey 1999;Gatenby \& Humphries 2000; Naples 2003). Our closeness and entanglement with our fields produce unique access to the contradictions of doing sex work. Simultaneously, we experience numerous moments of ethical trouble and unease connected to the processes that we are initiating, translating activist knowledge into academia. While our practice as activists allows us to remain accountable to our activist friends and colleagues, we also know that translation processes can never be controllable, are always already unfaithful (Haraway 1988), and at least partly respond to our need for self-accumulation as 'sex work experts' and 'sex work researchers' (Bournot-Trites \& Belanger 2005; Dewey \& Zheng 2013).

In practice, we maintain ongoing communications with members of these organisations about our research, including feedback and, where possible, public or group presentations. Interestingly - and this may well represent one of our moments of unease - members of both organisations have expressed a desire that we use the organisations' real names in our research outputs. We take this request as a sign of trust, and we know that this also indicates the need for publicity for a type of work that often goes unseen in research and the media. However, as academics, we are aware that being activist researchers cannot be seen as a guarantee against ethical problems. Our research results are published and thus available for anybody to reinterpret in ways which may damage the organisations beyond their - or, for that matter, our - reach or ability to respond. Moreover, in this article we produce an analysis which may at some stage not be welcome among parts of the organisations concerned, and could cause internal conflicts. Therefore, in order to protect our participants and our collaboration with them, we have chosen to anonymise the material. 
respectively. In both countries, prostitution is regulated by special laws that have introduced forms of legalisation. These laws frame sex work as a form of work, and sex workers are treated as workers, in that they have to pay taxes and - at least in principle - enjoy some of the rights and protections associated with other forms of work, such as pensions and health insurance. In Switzerland prostitution is a tolerated activity based on economic freedom, with third party organising and soliciting decriminalised in 1992, although the 1942 Penal Code provides for Cantons to write their own specific regulations on sex work. In Germany, prostitution has been a legal activity since 1943. However, it was deemed 'immoral', and there were regulations limiting it to defined areas ('zoning') and imposing mandatory medical testing on sex workers. The immorality of prostitution and the medical tests were abolished in 2001 (law ProstG 2001, BJF 2001), but the Federal states are still free to impose 'zoning' or other forms of regulations.

2.6 Moreover, these two countries display a relatively strong tradition of sex worker organising, including regular interventions in media and political platforms. In Switzerland, ProCoRe is a well-established network that connects individuals and about twenty organisations promoting sex workers' rights all over the country. Germany has a strong history of local sex workers' support and lobbying organisations, such as Hydra e.V. in Berlin (http://www.hydra-berlin.de) and Dona Carmen e.V. in Frankfurt (http://www.donacarmen.de). In 2013 the national professional association for erotic and sexual services was founded (http://berufsverband-sexarbeit.de). These groups have been crucial both in improving and in criticising laws regarding prostitution. In particular, they have challenged current reforms on account of the exclusion-effect they produce against certain categories of workers, in particular migrants, who are subject to lasting forms of institutional discrimination. For instance, this operates through the compulsory requirement for sex workers to register. Such a requirement is present in Switzerland, where workers have to register with the police in several Cantons including Geneva and Zurich, and it has recently been reintroduced in Germany with the 2016 reform (A Diverse Group of Berlin-based Sex Workers 2016; Bmffsj 2016; Doljinsek 2016).

2.7 The Sophie project organises workshops in a large German city reaching out to workers of different ethnicities, nationalities, migration statuses, classes and gender identities working in different sectors, such as streets, bars, flats and brothels. It also provides one-to-one peer counselling to people who are considering working as sex workers or who want to move between different sectors of the sex industry. Sophie is connected to and funded through an established organisation that provides support, advice and counselling to sex workers. In a way, Sophie may be seen as part of a tradition of outreach projects established across Europe from the 1990s onward in order to offer health, legal, and counselling services to a hard-to-reach population, oriented towards 'harm-reduction' and offered in a 'low threshold' way. (see TAMPEP) Initially driven by sex workers themselves, these projects, developed in reaction to the HIV/AIDS pandemic, became increasingly institutionalised. However, they remain structurally underfunded and subject to political and ideological attacks made by those who believe that supporting sex workers de facto equals promoting prostitution. Sophie represents a partial exception in this context, in that it is a sex worker-led collective education project.

2.8 The peer educators (from here onward 'the peers') do regular outreach to workplaces to promote their workshops and to make themselves known to workers and owners or other staff. Workshops may take place in German, Spanish, Romanian, Bulgarian, English and Thai, and the participants are usually a mix of German, non-EU and EU migrants. The conversations span a large variety of topics, including experiences of migration, the legal situation, how to deal with clients, relationships and societal stigma, knowing one's boundaries, how to work more safely, train in different areas of the industry such as BDSM, how to get support to change jobs completely, and many more. There is no predetermined agenda: the peers tend to adapt to the composition of the workers involved, and may spend the workshop talking about just one of these topics. At the end, information about existing support organisations is given, contacts are exchanged, and access to social events and networks is provided.

2.9 BodyUnity is an organisation of sexual assistants for people with disabilities that organises peer supervisions (called 'inter-visions') for sexual assistants, as well as training for becoming a sexual assistant. The last decade has seen an increase in public interest and academic debate on the subject of how sex-related services may or may not facilitate disabled people's access to sexuality (De Boer 2015; Garofalo Geymonat 2014b; Kulick \& Rydström 2015; Fritsch et al. 2016). In Europe arguably the strongest role in this change has been played by new and vocal grassroots organisations, usually driven by disabled activists, in countries such as France, Switzerland, Belgium, Spain, Italy, and Hungary. In some instances they have claimed a space of recognition from regional or national legislators (see for instance European Platform for Sexual Assistance). BodyUnity sees itself as part of this larger international 'movement', and in fact includes members from four different European countries. However, BodyUnity is somewhat different in that it is an organisation created by sexual assistants for sexual assistants, 
2.10 Sexual assistants at BodyUnity explicitly discuss what kind of practices might improve the relationship quality, communication and intimacy with clients with disabilities. For example, there is a shared understanding that sessions be no shorter than one hour, a period of time that is considered the minimum for practicing a good relationship with a disabled client. Moreover, before starting the assistance itself, members recommend a 'preliminary meeting' - a non-sexual encounter, ideally in person or on Skype, allowing the potential client and the assistant to see each other and discuss their expectations and boundaries, and subsequently to decide whether they want to initiate the assistance. Moreover, the trainees are trained to relate to the client's team of personal assistants and family carers.

2.11 Interestingly, BodyUnity members tend to embrace a discourse of reciprocity with the clients, including around aspects of pleasure. Key activists in the field go so far as thinking that sexual assistants should be able to experience sexual pleasure and even orgasms with their clients. Obviously this question is very contested. In any case, issues of intimacy, pleasure, boundaries, and power (im)balances are at the centre of the collective training and inter-vision sessions organised by BodyUnity.

2.12 There are major differences between the two organisations and the people involved in them, in particular as regards working practices and their participants' socio-economic positions, access to resources, and alternative income-generating activities. The members of BodyUnity are mostly in their 40 s or 50s, women and men from different countries but all of them of European nationality, and in their very large majority white. Most of them work or are retired from care professions such as nursing, social work, or body work such as massage, and some also practice or have practiced 'ordinary sex work'. In addition to a strong ethical motivation with regards to disability and socio-sexual inclusion, sexual assistance is seen by most participants as a good way to add an extra income to their often precarious economic situation.

2.13 Conversely, participants in the Sophie workshops constitute a much more diverse group, with different national and educational backgrounds, migration statuses and language skills. They are aged from 18 to over 70, the majority of them between their early 20s and mid 40s. Some of them have other occupations, but many live solely off sex work. The majority are independent, but some are in relationships of control and exploitation, often with their partners.

2.14 The organisations differ in terms of third-party involvement and their relationship to the public authorities. Indeed, in the case of the Sophie project, we are dealing with practices that are affected by the actions of tax authorities and police, including raids, fines, and even arrest and deportation for some. On the other hand, sexual assistance is largely ignored by the authorities, even though in principle it remains regulated, and therefore threatened, by the same prostitution law.

2.15 In sum, the Sophie project works to improve working conditions at the margins of a complex and developed sex industry where a section of the workers experience serious forms of exploitation and control from third parties, as well as repression from the public authorities. BodyUnity, conversely, deals with a small market niche where third party exploitation is not an issue, state intervention is very limited, and members can take the time collectively to imagine what respectful non-exploitative forms of paid sexual service would look like. However, even across these very different contexts these collectives share some similar areas of concern, analysis, and recommendation. In particular, insofar as they devote their attention to issues of autonomy and consent.

\section{Autonomy as a Process}

3.1 BodyUnity was born out of a larger and older organisation, Sex\&Love, for reasons which may well be relevant to the present paper. Several participants reported that when they were part of Sex\&Love they felt that the group supervision sessions for sexual assistants were becoming invasive discussions, in which the supervisors - who were educators in the field of sexuality and disability - ended up exerting forms of control and discipline, trying to impose what the sexual assistants should or should not do with their clients, whom they should accept as clients, and so on. As one of the participants told Giulia, this was not only tiring, but also dangerous in an activity in which 'the relationship with clients is, and should remain, personal and personalised'. As an another assistant put it 'each assistant must remain free to find their own very particular limits with that particular person they have in front of them at that particular moment'. According to the founding members of BodyUnity, this was one of the main reasons for creating an organisation that would allocate central roles to those who can better understand the questions of boundaries, intimacy and consent, because they themselves have experience of sexual assistance - and that is why other kinds of members, including disabled activists, therapists and sexologists, have only limited power of decision within BodyUnity. 

further forms of intrusion, control and stigmatisation from the public authorities. For example, one participant reported that 'they might want to impose norms of what is a 'good and just sexuality', or who is suitable or not suitable to offer a service or indeed receive it'. Another fear of depending on public funding is that it would somehow imply exposing the sexual assistants' real identities. The anonymity of BodyUnity members is indeed a priority for the organisation. Stigmatisation, discrimination, and violence are strong here, as evidenced by a negative episode reported to Giulia by a member who exposed herself in the media and was subsequently followed home by an unknown man.

3.3 Each of the peers at the Sophie project speaks several languages and, as a group, the peers have deep knowledge of several cultures, sex industries, and legal systems, and regularly attend specific training in topics such as diversity, sexual health or counselling. Their experience of sex work spans from working in brothels, escort agencies, streets, night clubs, web cams and BDSM. Most of them are migrants, and some have been through experiences of heavy exploitation and trafficking. However, when talking about their project, the peers insist that they are not 'experts' or any more knowledgeable than other sex workers. They define Sophie as a 'horizontal collective educative work', using the terms 'critical' and 'radical pedagogy' (Freire 1951; Rancière 1998) to refer to the sharing of their experience of sex work and stigma. Crucially, as one of the peers put it, 'what makes the difference is that we have the opportunity to collectively reflect upon our own experiences'.

3.4 In the German context, this approach emerges in opposition to a top-down model in which the state defines itself as the expert in the field. In particular, Sophie is very critical of the new prostitution law (Bmffsj 2016), which introduces a form of mandatory 'medical briefing' that sex workers are asked to undergo with a (not yet defined) state authority, every two years (or every six months for those who are under 21) in order to get legally registered. In this process, experts without direct knowledge of sex work will decide who is able to 'willingly' work as a sex worker, and who is a victim of trafficking and cannot be allowed to work legally. This procedure, according to one of the peers, 'will inevitably discriminate migrant sex workers and all those who do not wish to get registered because of the fear of being exposed'. The Sophie project instead focuses on facilitating dialogue and exchange among sex workers, focusing on the options that sex workers actually have. It avoids suggesting that there is, as the same peer sharply put it, 'one way to do sex work, one way to migrate, one way to love one's family, one way to be emancipated'.

\section{Beyond Consent}

4.1 In order to access the training organised by BodyUnity, candidates needed to overcome a very complex selection process, including proving that they had no criminal records related to sexuality, providing a letter of motivation and CV, and being interviewed. After that, a selected group took part in a weekend in which trainers could observe the group dynamics. In the meantime, the candidates had the time to make their decision on whether to start the training or not. Only after a month was the final group created. Certainly, these are all elements which should be analysed in terms of the consequences they have in reproducing particular characteristics among sexual assistants. Members of BodyUnity are overwhelmingly white, have a European nationality, and are from middle or lower-middle class backgrounds. A minority of them have a disability. Most of them identify with their 'being sexually a little crazy' as one put it - non-monogamous, BDSM, swingers, with disabled or same-sex partners.

However, BodyUnity do not see this complex selection process as a matter of wanting to exclude certain categories of people. Indeed, at least in principle, the group recognises the need to be more inclusive of social diversity. Crucially, the organisers of BodyUnity state that there might be very competent sexual assistants who are not trained, and that the training and the membership to BodyUnity is essentially a community to rely on. Also, along with other groups in Europe, their goal is to eventually spread what they see as better practices among all those who engage in sexual assistance, whether they are trained members of the organisation or not.

Through the interviews it became clear that the selection is instead understood in relation to the need to promote a substantial and ongoing process of consent formation. Consent emerged in a number of interviews, including with regard to age - 'it might be better to be a bit older in order to be more in touch with what you want' said one of the trainers explaining why they tend to prefer trainees above the age of 30 - or in commenting on the importance of being 'out' to one's intimate partners or friends - 'for they may help you keep up your level of consciousness' said the same member. The theme of 'consciousness' also recurred when discussing relationships with clients. References to 'consciousness' or the 'balance' of the relationship often appeared to be ways of talking about issues of dependence and power relations. In discussing these topics members often use comparisons with other professions like psychotherapy, care, 
and 'ordinary sex work' - professions that they insist are different from sexual assistance, but at the same time close enough to be considered in the elaboration of good practices. For instance, payment for sexual assistance is seen not only as recognition of the labour involved, but also, as in psychotherapy, a specific element useful for framing the relationship between assistant and client. It establishes a clear distance, but also simultaneously allows for more closeness thanks to a clear framework that does not leave the client with feelings such as emotional debt or the assistant with guilt for not having provided enough.

According to BodyUnity members the price should therefore be a clear one, not too low but also not too high, because raising prices could become a way of taking advantage of clients who are often in a situation of vulnerability and emotional dependence. On the other hand, this reflection on economics and dependence also extends to the worker: the dominant discourse in the group is that sexual assistants should not become entirely dependent on sexual assistance, so that they can still say no to a potential or existing client and refer them to someone else. Indeed, in the selection process for the training, BodyUnity also includes a requirement that the candidates have some other source of income, which is typically another job, which may be 'ordinary sex work'.

Interestingly, during the Sophie workshops, participants often engage in conversation about 'consent', 'choice', or, as many would have it, 'wanting or not wanting' to work as sex workers. The discussion generally involves the need for money, and the need to balance this with the conditions under which the money is made, as it is well illustrated by this sentence by a workshop participant:

Sure I must work, every one must work, not just me. You must, she must. I don't want to work in the factory anymore, so I try other things. But if I want to work as a prostitute it does not mean I want to do anything, or work anywhere.

With the words of one of the peers:

\begin{abstract}
In all jobs it is undesirable to do something against your will just because you need the money. But in sex work probably more so. We would always advise a sex worker not to do something they don't want to do, even if they have agreed to do it. Rather than saying yes once and for all, it is important to interrogate oneself constantly, and to have the possibility of saying no to a client whenever you feel that way, at the cost of losing income.
\end{abstract}

So a lot of the Sophie project's discourse and activities are about knowing your boundaries, setting them in advance, and constantly monitoring them and how you feel about the work. The peer workshops bear witness to the great diversity and unequal resource-access among participants, as well as the subjective and relative nature of their needs and desires. As such, discussing boundaries and consent may mean very different things to different people. For instance, it can mean exploring what parts of the job are preferable for each participant and trying to see whether they can adjust or change their work accordingly in order to be less stressed or burned out by it, for instance by moving from a brothel to independent work, changing venue or section of the branch. It can mean looking for ways of saving more money, working less, or recruiting reliable regular clients who pay better. It can mean talking about ways to end third parties' abuse or exploitation by sharing own successful escape or liberation stories. It can also mean promoting people's access to jobs other than sex work, and having more independence within the industry. The aim appears always to be maximising income and minimising uncomfortable or exploitative relations.

Crucially, the peers insist that good sex work does not only mean sex work practiced by those who are not financially dependent on it. As one of the peers said on one occasion:

What is money if you have no self-respect and no health? I know this wealthy escort girl who could live off her family money, freaking out about ever saying no to a job, and really burning out. And you have this other single mother with only sex work as an income who is so selective and would rather work less than fuck herself over $[\ldots]$

The peers, on the other other hand, avoid suggesting that the attitude of the individual sex worker is what makes all the difference to a good form of sex work. This is well illustrated by this quote by one of the peers:

I do do some clients when I don't feel like it sometimes, it does not always work this 'listen to your guts' thing. I try not to be hard on myself though. When I do things that I could avoid, I remind myself that I really needed that money, that is why I did it, and not cause I am bad at caring for myself. Who always feels like going in to work? Then I feel a bit better. 
change the material constraints they face. Therefore 'professionalisation' in this context may be

identified as the space of getting less financially dependent on sex work, including through other forms of sex work, and simultaneously maintaining the highest possible level of control over when and what to do with whom in sex work.

4.11 Both in the context of Sophie and in the context of BodyUnity, autonomy and consent therefore emerge not as fixed points in which one finds or does not find oneself, but rather as dynamics of change that are experienced at the individual level and that can be promoted through peer collectives.

\section{The Three Traps}

5.1 As they address issues related to the quality of work and life, consent and autonomy, our participants also engage with some of the questions that are traditional in the field of quality of work and professionalisation, namely working standards or rules, income ('money') and (professional) identity. However, while these areas are usually associated to secure work and successful professionalisation, our participants treat them with extreme caution, and seem to rather perceive them as 'traps' to be avoided in order to be happier, and do a better job, as a sex worker or sexual assistant.

\section{The trap of rules}

First of all, across the two collectives there appears to be a strong sense that there should be no rules on how to do sex work imposed by anyone else - whether it is managers, doctors, public authorities, or even other sex workers. In fact, these sex providers show a particularly strong attachment to setting their own rules at the individual level, and being able to have these rules respected while also being able to change them at any time.

During the workshops at the Sophie project there are a lot of conversations regarding what to do when a client gets pushy about a certain sexual act or about a certain form of emotional or relational engagement that the sex worker is not prepared to offer. Sophie project participants share tips on how best to maintain a space of calm and focused negotiation and renegotiation at all times in order to be able to say no if suddenly something does not feel right - possibly without losing clients and the good contact with them.

5.4 A large part of the training sessions at BodyUnity appear in one way or another to involve - including through mediation or body awareness - exercises relating to how to remain, as the participants themselves would say, 'present in the moment' of the encounter with the client, 'checking in' with one's own boundaries and following them continuously. This is also one of the reasons why BodyUnity advises their members against giving a detailed description of their sessions to their clients beforehand, instead limiting the specification of their 'contract' to a certain amount of time, and then clarifying what general boundaries they have with all clients.

This approach certainly is in line with the need to protect oneself and prevent discomfort, client violence and burn-out, whose importance studies about the risks connected to sex, body and intimate work have indicated (Vanwesenbeeck 2005; Sanders 2004, 2005; Wolkowitz et al. 2012). Simultaneously, many sex workers and sexual assistants in these collectives also seem to see this working philosophy - keep your own rules and feel free to change them if they feel wrong - as a positive and constructive way to do better sex work and make more money. Staying in touch with oneself, elaborating one's own rules and limits yet allowing oneself to be surprised or change one's mind in between are discussed as making it more likely that one can create good contact with the clients. It increases their pleasure and fun, but also one's own pleasure and fun, and therefore provides for a better sex service. As one Sophie project peer put it:

It is not about having orgasms. It is also not about never having them either because it's just work. If you enjoy any work you do - it's better! It does not mean you have to enjoy it though. The more relaxed you are, the more open about what may be enjoyable, the less stressed about 'having to enjoy' and the least machinelike you act, the better I think. For you, for the client and for your pockets!

\section{The trap of money}

A second recurrent theme appears to be that of how much time and energy it is best to dedicate to sex work or sexual assistance, and in turn how much one should depend on income from sex work and sexual assistance. In particular participants from both groups appear to be particularly aware of the fact that it is better not to become a full-time sex worker or sexual assistant or to make it one's exclusive income-generating activity on a stable basis. Indeed in the case of the sexual assistants at BodyUnity, this translates into a requirement in the selection process for the training course, stipulating that the 
candidate must also have another job or source of income. Even though it is clear that for some individuals conditions may later change - and indeed for some sexual assistants they have changed this requirement serves to indicate that sexual assistance should ideally be one among several activities. Moreover, some sexual assistants get worried when they are overly economically dependent on one particular client. It is not rare to hear this kind of worry: What would happen if I wanted to stop seeing this client tomorrow, if they needed to stop, or even if they died?

These concerns about not relying too much or for too long on sex-work money were shared by some of the sex workers involved in Sophie workshops. Furthermore, participants in the Sophie workshops are at times supported in finding ideas for other jobs or training courses. This appears to be substantially different from an insistence on leaving sex work, which we find in the many 'exit projects' offered to sex workers across Europe and beyond. Indeed, Sophie project participants often seem to care less about leaving the industry altogether - although that may happen, too - than being able to combine sex work with other forms of labour, so as to be more independent within sex work. As one of the participants in Sophie project workshops put it: 'Personally, I would love to keep doing this, maybe even after I can open my own shop, I could do it for just one or two days a week'.

\section{The trap of identity}

Finally, a third aspect recurring across the groups has to do with one's professional identity, and its management. Participants from Sophie and from BodyUnity invest a lot of their collective energies discussing self-esteem, trying collectively to counter the stigmatisation they experience from people, institutions, and the media. In this sense, the possibility of accessing a community of colleagues that is not controlled by others - as in the case of workshops, peer 'inter-visions' and training - is generally experienced by participants from both projects as making a remarkable difference to their wellbeing. One of the participants at BodyUnity says:

When I don't see you guys for a long time, I lose the sense of who I am, and what I am doing here. I feel so recharged after the meetings!

A lot of the conversations within both groups focus on internalised shame and positive representations of sex work and sexual assistance as valuable, socially-useful activities, and so on. As a participant in a Sophie workshop puts it:

\footnotetext{
Are you proud of being a sex worker? Me, I am proud of what I do, and how I do it, at least almost all the time... People out there don't realise how important we are, how many people we support and listen to, in a different world we would be called heroes, not spat upon!
}

At the same time one of the main areas of concern and of advice is how to work in ways that do not expose one's real identity, as well as 'who to tell or not to tell' that one is a sex worker or sexual assistant. As we have seen, both organisations strongly oppose any kind of forced 'coming out' or public registration. Stories circulate of 'being 'outed' to family, to friends, partners, or coworkers in other jobs. These are stories full of consequences, in terms of unhappiness, discrimination, and break-ups. For some of the sex workers involved in the Sophie workshops, and for BodyUnity's sexual assistants, talking to the media might also be an option, while initiating legal actions may sometimes expose one's real identity. The discourse within both groups seems to maintain a safety-first approach to media disclosure, and they instead tend to share experiences that suggest extreme carefulness. These are the words of one of Sophie workshop participants:

I was just excited about doing it, it was just the start, and I was not thinking too much about the consequences, the journalist was alright, so I said it in an interview for public TV in my country, and oh god, I really wish I hadn't - I have lost friends and still fear more damage for it.

The aspect of protection from the effects of stigma after professional disclosure is ambivalent. Some members of both Sophie and BodyUnity who speak publicly as sex workers or sexual assistants consider their ability to escape the difficulty of leading a double life to be an advantaged position. Yet they are also aware of the strong and difficult implications this can have in their lives and therefore tend not to preach being out as something central to good working and living conditions - and, in fact, not even for a good model of activism.

\section{Making sense of contradictions}

5.12 Looking at the areas of shared reflection and recommendations that we have identified as the three 'traps', we may well be struck by a certain ambivalence. What kind of projects strengthening workers and professionals would advise against fully embracing one's professional identity, while advocating trying to avoid working full-time, always working in other jobs too, and trying to refuse any rule on how 
to work? These messages do not seem very oriented to professionalisation or unionisation, within a

standard perspective. For some, these elements may contribute to a reading that dismisses sex workers' organisations as individualistic or ultra-liberal: sex workers and sexual assistants ask for the right to do sex work or sexual assistance and state that they choose this work, but then they are not ready to follow any rules or to accept any responsibility towards their clients, they evade public controls and want to remain hidden. While some sex workers may, indeed, feel individualistic, ultra-liberal, or even antisocial, this interpretation does not help us when we are trying to understand collective organisations such as Sophie and BodyUnity, whose work is based on a strong political and ethical view of society and justice. How, then, can we make sense of these areas of collective reflection as a part of the knowledge and actions produced by these organisations?

5.13 Partly, these contradictions may only look like contradictions from the perspective of other, different, mainstream kinds of labour, typically concerning, in contemporary Europe, only a mostly white, straight, male, non-migrant minority of subjects whose income-producing activities or employment are legitimate, socially valued, and do not involve engagement of relational and identity resources, or risks connected to stigmatisation, violence and criminalisation. Sex work and sexual assistance is instead largely the work of young, ethnicised people, queers, migrants and women, who have little economic opportunities and social and economic rights, a high mobility rate, and may engage in sex work occasionally, for short periods of time, out of emergency, along with several other income-making activities, family duties and 'sexuo-economic relationships' (Tabet 1991) at different points in time or simultaneously (Garofalo Geymonat 2014a). For these groups of people, these elements of 'good work', professionalisation - and the models of welfare, citizenship and unionisation to which they correspond have hardly ever been relevant, and are even less so in the contemporary context of austerity and antimigrant policies prevalent across Europe. Even in contexts in which sex work is legal, the many forms of stigmatisation, discrimination and criminalisation that sex workers and sexual assistants experience may explain their reluctance to embrace employment and public rules or a full professional identity, or indeed to invest in sex work as a full-time career.

5.14 Moreover, our participants show a sophisticated understanding of the mobilisation of the self and the body involved in sex work and sexual assistance, which makes it particularly hard to standardise the service and separate it from one's person. This particular mobilisation has been extensively been theorised by scholars of sexual, intimate, body and risky labour (Sanders 2004, 2005; Bernstein 2007, Boris \& Salazar Parreñas 2010, Lever \& Dolnick 2010). As one the participants in a Sophie workshop put it:

It is a very delicate affair, because you touch people, and get touched, in very special ways. Sex is very personal, you can never really become like a machine, can you?

5.15 Among others, Julia O'Connell Davidson has usefully discussed how, behind the rhetoric of 'sex work as any other work', in fact sex workers do not really want to be recognised as 'sellers of fully commodifiable labour/services like other workers' (O'Connell Davidson 2014: 522). Such an approach gives conceptual confirmation to some of the main statements produced by the sex workers' movement in Europe in the last decade. Texts such as the highly exemplary Sex Workers in Europe Manifesto (2005) point to the fact that sex workers collectively demand their freedom to determine the conditions under which they conduct sex work, and refuse both employers' and the state's intrusion into the determination of their profession.

\footnotetext{
The fact that sex becomes work does not remove our right to have control over who we have sex with or the sexual services we provide or the condition under which we provide those services. We demand the right to say no to any client or any service requested. Managers must not be allowed to determine the services we provide or the conditions under which we provide them - whether we are employees or 'self-employed'. (ICRSE 2005)
}

5.16 These demands are to a certain extent contradictory for a workers' movement. However, the radical refusal of wage labour, union mediation, and the insistence in creating direct forms of self-organised labour outside of the control of the state and capital is something that is recurrent in the history of the labour movement. In fact, the collective practices, demands and recommendations of sex providers could be usefully read together with the experiences of other movements of workers, such as the Workerist Autonomist movement in Italy (Virno \& Hardt eds. 1996), which have also developed similar approaches implying dis-identification from work and a lack of confidence in collective agreements.

5.17 Our materials may be seen as adding to the debates on sex work, quality of sex work, and sex workers' unionisation, from a perspective of concrete collective organising and thinking. Interestingly, our participants produce peer counter-rules, shared recommendations, and collective spaces that are oriented not only to protecting themselves from exploitation, and avoiding damage to their own selves, 
but also to maximising their chances of having fun and allowing for ways of experiencing pleasure at work. In other words, they appear to delineate a constructive approach to 'good sex work' and 'good sexual assistance' which may imply an increase in workers' income and better working practices, but ultimately tends to the recognition that quality of life and quality of work are inseparable. The only acceptable rule, in this scenario, becomes the freedom to set and break one's rules, and to remain present to oneself at all points. In other words, the freedom to be happy.

\section{Conclusion}

In spite of an increasingly vast literature on sex work as work, studies on the quality of work currently remain underdeveloped. One of the reasons might be that sex workers and sex work activists may feel suspicious of a field of studies which may run the risk of objectifying and standardising sex work experiences, therefore challenging sex workers' autonomy and increasing processes of workers' alienation and exploitation. However, simultaneously, a number of experiences of workers' collective action in current Europe demonstrate a concrete engagement with themes connected to work and life quality - for instance through peer workshops, training for workers, or recommended practices. Our paper has shown ways in which this field may benefit from an engagement with these projects, which in turn requires that researchers (and vice versa activists) take the risk of occupying the uneasy position of being at the same time researcher and activist. Being simultaneously outsiders and insiders allowed us to explore some of the most contradictory 'professionalising' aspects of two self-organised projects, one of peer sex worker educators in Germany, and one of sexual assistants in Switzerland. Indeed, these aspects may not look 'professionalising' in the classic sense of the word, and indeed they run against working and service standardisation, collective contracts, professional identity, and full time employment. However, these classic elements of 'good work' are primarily built around forms of work, groups of workers, and models of welfare, that have hardly ever been relevant for the people - largely women, queers and ethnicised people - engaging in sex work, and still less so in the contemporary context of neoliberal austerity and reduced migrants' rights across Europe. These projects are 'professionalising' in the sense that they propose forms of collective guidelines elaborated by sex workers and sexual assistants, in a way that builds on and develops their professionality and suggests how sex work functions as - and can be understood as - a profession.

The gap between sex workers' and sexual assistants' collective practices and knowledge and classic ideas of 'good work' and workers' organising is particularly noticeable in countries such as Germany and Switzerland where the state offers sex workers forms of legalisation and control that are often contested by activists and refused by most workers. That is to say, our participants criticise the ways in which public authorities and discourse risk instrumentally mobilising quality of work, consent and autonomy in order to classify 'real', 'legal', 'free', 'good' sex workers (or sexual assistants) and exclude and criminalise those who are seen as 'victims' (or indeed 'perverts'). They instead appear to redefine the centrality of consent and autonomy as never-ending processes that constantly need to be struggled for both individually and collectively.

While our participants call for the recognition of sex work or sexual assistance as a valuable service, they remain profoundly ambivalent towards the idea of having their services 'professionalised' and regulated along the lines of other professions, and they appear to agree in refusing any rules - about how to work and who is the real good sex worker or sexual assistant - that are imposed by the state, managers, doctors, or even other sex workers and 'unions'. Also, they are wary of making it one's exclusive career and source of income. Rather, they reclaim a space of spontaneous and pleasurable connection with clients that can be interrupted only at their own discretion, indicating that a form of radical autonomy might be a good way to think about better quality of work in the sex industry.

\section{Acknowledgements}

Thanks to the COST Action IS1209 'Comparing European Prostitution Policies: Understanding Scaled and Cultures of Governance' for its financial support to our collaboration, and to the members of the ProsPol Workgroup on Economic Dimensions for their comments on earlier versions of this paper.

\section{References}


workers', Open Democracy, 8 July 2016: https://www.opendemocracy.net/beyondslavery/diversegroup-of-berlin-based-sex-worker-activists/german-law-endangers-sex-workers.

AGUSTIN, L. (2007) Sex at the Margins: Migration, Labour Markets and the Rescue Industry. London: Zed Books.

AMNESTY INTERNATIONAL (2016) "The human cost of "crushing" the market: Criminalisation of sex work in Norway': https://www.amnesty.org/en/documents/eur36/4034/2016/en/.

ANDRIJASEVIC, R., ARADAU, C., HUYSMANS, J. and SQUIRE, V. (2012) 'European citizenship unbound: Sex work, mobility, mobilisation', Environment and Planning D: Society and Space, Vol.30, Issue 3, p. 497-514. [doi:10.1068/d10210]

ANDRIJASEVIC, R. (2013) 'Sex Workers and Migration, Europe' in I. Ness (ed.) The Encyclopaedia of Global Human Migration, Malden, MA: Wiley-Blackwell, p.1-5 [doi:10.1002/9781444351071.wbeghm481]

BERNSTEIN, E. (2007) Temporarily Yours: Intimacy, Authenticity, and the Commerce of Sex. Chicago: University of Chicago Press. [doi:10.7208/chicago/9780226044620.001.0001]

BJF (Bundesministerium der Justiz und für Verbraucherschutz) (2001) Prostitutionsgesetz: http://www.gesetze-im-internet.de/prostg/.

BMFFSJ (Bundesministerium für Familie, Senioren, Frauen und Jugend) (2016) Prostituiertenschutzgesetz verabschiedet: http://www.bmfsfj.de/BMFSFJ/Service/volltextsuche,did=226524.html.

BORIS, E. and SALAZAR PARREÑAS, R. (Eds.) (2010) Intimate Labors. Cultures, Technologies and the Politics of Care. Stanford: Stanford University Press.

BOUMA, G. and ATKINSON, G. (1995) Handbook of Social Science Research. Oxford: Oxford University Press.

BOURNOT-TRITES, M. and BELANGER, J. (2005) 'Ethical dilemmas facing action researchers', Journal of Educational Thought, Vol. 39, Issue 2, p. 197-215.

BREKKE, J.K. (2008) 'Organising in the dark. Interviews about migrants' struggles' Mute, Vol.2, Issue 7 London: OpenMute Press http://www.metamute.org/editorial/articles/organising-darkinterviews-about-migrants-struggles.

CARADONNA, A. (2016) 'We speak but you don't listen: Migrant sex worker organising at the border', Open Democracy: https://www.opendemocracy.net/beyondslavery/sws/ava-caradonna-X-talkproject/we-speak-but-you-don-t-listen-migrant-sex-worker-organisi.

COBBLE, D. S. (2010) More intimate unions in E. Boris and R. Salazar Parrenas (Eds.) Intimate Labors. Cultures, Technologies and the Politics of Care. Stanford: Stanford University Press.

CROWHURST, I., OUTSHOORN, J. and SKILLBREI, M-L. (2012) 'Introduction: Prostitution Policies in Europe', Sexuality Research and Social Policy, Vol. 9, p. 187-191. [doi:10.1007/s13178-012-0100-7]

CRUZ, K. (2013) 'Unmanageable work, (un)liveable lives: The UK sex industry, labour rights and the welfare state', Social \& Legal Studies, Vol. 22, Issue 4, p.465-488. [doi:10.1177/0964663913484639]

DE BOER, T. (2015) 'Disability and Sexual Inclusion' Hypatia Vol. 30, Issue 1, p. 66-81 [doi:10.1111/hypa.12118]

DEWEY, S. and ZHENG, T. (2013) Ethical Research with Sex Workers: Anthropological Approaches. New York: Springer.

DITMORE, M. 2007 'In Calcutta, sex workers organize', in P. Ticineto Clough (ed.) The Affective Turn. Theorizing the Social, Duke University Press, Durham, p. 170-186.

DOLJINSEK, S. (2016) 'Sex workers fight against compulsory registration and identification in Germany', Open Democracy: https://www.opendemocracy.net/beyondslavery/sonja-dolinsek/sex-workersfight-against-compulsory-registration-and-identification-in.

FREIRE, P. (1951/2000) Pedagogy of the Oppressed. London: Bloomsbury Publishing.

FRITSCH, K., HEYNEN R., ROSS A-N. \& VAN DER MEULEN E. (2016) 'Disability and sex work: developing affinities through decriminalization' Disability \& Society, Vol. 31, Issue 1, p. 84-99. 
GALL, G. (2006) Sex Worker Union Organizing: An International Study. Basingstoke: Palgrave Macmillan.

GALL, G. (2007) 'Sex worker unionisation: An exploratory study of emerging collective organisation', Industrial Relations Journal, Vol. 38, Issue 1, p. 70-88. [doi:10.1111/j.1468-2338.2007.00436.x]

GAROFALO, G. (2010) Sex Workers' Rights Activism in Europe: Orientations from Brussels in Ditmore, M.H., A. Levy, A. Willman (Eds.) Sex Work Matters. New York: Zed Books, p. 221-238

GAROFALO GEYMONAT, G. (2014a) Vendere e comprare sesso, Bologna: Il Mulino.

GAROFALO GEYMONAT G. (2014b) 'Oltre il dibattito pubblico, ma non oltre la critica: pratiche di assistenza sessuale in Europa' in M. Ulivieri (ed.) LoveAbility. L'assistenza sessuale per le persone con disabilità. Trento: Edizioni Centro Studi Erikson, p. 99-114

GAROFALO GEYMONAT, G. (2016) Sex work and sex workers' unionization' entry in Naples, N. (ed.) The Wiley Blackwell Encyclopedia of Gender and Sexuality Studies. Malden, MA: Wiley-Blackwell, p.1-5 [doi:10.1002/9781118663219.wbegss604]

GAROFALO GEYMONAT, G. and MACIOTI, P. G. (Eds.) (2016) 'Sex workers speak: Who listens?' BTS Short Course, London: Open Democracy.

GATENBY, B., HUMPHRIES, M (2000) 'Feminist Participatory Action Research: Some Methodological and Ethical Issues' Women's Studies International Forum. Vol. 23, Issue 1, p.89-106. [doi:10.1016/s0277-5395(99)00095-3]

HARAWAY, D. (1988) 'Situated knowledges: The science question in feminism and the privilege of partial perspectives', Feminist Studies, Vol. 14, Issue 3, p. 575-599. [doi:10.2307/3178066]

HARDT, M. (1999) 'Affective Labor', Boundary 2, Vol. 26, Issue 2: p. 89-100

HARDY, K. (2016) 'Uneven divestment of the State: Social reproduction and sex work in neodevelopmentalist Argentina', Globalizations, Vol.13, Issue 6, p. 1-14. [doi:10.1080/14747731.2016.1163882]

HARDY, K. and SANDERS, T. (2015) 'The political economy of lap dancing: Intersectional precarities and women's work in the stripping industry', Work, Employment and Society, Vol. 29, Issue 1, p.119136.

ICRSE (International Committee on the Rights of Sex Workers in Europe) (2005) Sex Workers in Europe Manifesto: http://www.sexworkeurope.org/resources/sex-workers-europe-manifesto.

ICRSE (International Committee on the Rights of Sex Workers in Europe) (2016) Exploitation. Unfair Labour Arrangements and Precarious Working Conditions in the Sex Industry: http://www.sexworkeurope.org/sites/default/files/userfiles/files/ICRSE_Exploitation\%20Report_April2016_04_final.pd

JACKSON, C. (2016) 'Framing sex workers' rights: How US sex worker rights activists perceive and respond to mainstream anti-trafficking advocacy, Sociological Perspectives, Vol. 59, Issue 1, p. 2745. [doi:10.1177/0731121416628553]

KEMPADOO, K., and DOEZEMA, J. (eds.) (1998) Global Sex Workers: Rights, Resistance and Redefinition. New York: Routledge.

KULICK, D.and RYDSTRÖM, J. (2015) Loneliness and its Opposite: Sex, Disability and the Ethics of Engagement. Duke University Press. [doi:10.1215/9780822375845]

LEVER, J. and DOLNICK, D. (2010) Call girls and street prostitutes: Selling sex and intimacy in Weitzer, R. (Ed.) Sex for Sale. London: Routledge, p. 85-100.

MACIOTI, P.G. (2014) 'Liberal zu sein reicht nicht aus. Eine progressive Prostitutionspolitik muss das «Hurenstigma» ebenso bekämpfen wie die Kriminalisierung von Sexarbeit'. Standpunkte 7/2014. Berlin: Rosa Luxemburg Stiftung.

MAI, N. (2009) 'Migrant workers in the UK sex industry', ISET, London Metropolitan University: http://www.uknswp.org/wpcontent/uploads/ESRC\%20Sex\%20Industry\%20Findings\%20Document\%20Final.pdf. 
MATHIEU, L. (2003) 'The emergence and uncertain outcomes of prostitutes' social movements', European Journal of Women's Studies, Vol. 10, Issue 1, p. 29-50. [doi:10.1177/1350506803010001788]

MAXEY, I. (1999) 'Beyond Boundaries? Activism, Academia, Reflexivity and Research', Area. Vol.31, Issue 3, p. 199-208.

MUÑOZ DE BUSTILLO R., FERNÁNDEZ-MACÍAS E., ESTEVE F \& ANTÓN J. (2011) 'E pluribus unum? A critical survey of job quality indicators', Socio- Economic Review, Vol. 9, Issue 2, p. 447-475. [doi:10.1093/ser/mwr005]

MORINI, C. (2007), 'The feminization of labour in cognitive capitalism', Feminist Review, Vol. 87, Issue 1, p. 40-59.

NAPLES, N. A. (2003) Feminism and Method: Ethnography, Discourse Analysis, and Activist Research. New York: Routledge.

NEGRI, A., HARDT, M. (1999) 'Value and Affect', Boundary 2, Vol. 26, Issue 2: p. 77-88

O'CONNELL DAVIDSON, J. (2014) 'Let's go outside: Bodies, prostitutes, slaves and worker citizens', Citizenship Studies, Vol. 18, Issue 5, p. 516-532. [doi:10.1080/13621025.2014.923703]

PITCHER, J. and WIJERS, M. (2014) 'The impact of different regulatory models on the labour conditions, safety and welfare of indoor-based sex workers', Criminology and Criminal Justice, Vol. 14, Issue 6, p. 549-564. [doi:10.1177/1748895814531967]

PHETERSON, G. (Ed.) (1989) A Vindication of the Rights of Whores. Seattle: Seal Press.

PHETERSON, G. (1993) 'The whore stigma: Female dishonor and male unworthiness', Social Text, Vol. 37, p. 39-64. [doi:10.2307/466259]

PLOWS, A. (2008) 'Social movements and ethnographic methodologies: An analysis using case study examples', Sociology Compass, Vol. 2, Issue 5, p.1523-1538. [doi:10.1111/j.1751-9020.2008.00091.x]

RANCIÈRE, J. (1991) The ignorant schoolmaster: Five lessons in intellectual emancipation. Stanford: Stanford University Press..

SANDERS, T. (2005) '"It's just acting": Sex workers' strategies for capitalizing on sexuality',Gender, Work \& Organization, Vol. 12, Issue 4, p. 319-342. [doi:10.1111/j.1468-0432.2005.00276.x]

SANDERS, T. (2004) 'A continuum of risk? The management of health, physical and emotional risks by female sex workers', Sociology of Health and Illness, Vol. 26, Issue 5, p.1-18. [doi:10.1111/j.01419889.2004.00405.x]

SANDERS, T. and HARDY, K. (2014) Flexible Workers, Labour, Regulation and the Political Economy of the Stripping Industry. London: Routledge.

TABET, P. (1991) Les dents de la prostituée: échange, négociation, choix dans les rapports économicosexuels' in Hurtig M., M. Kail, H. Rouch (eds.) Sexe et Genre. De la hiérarchie entre les sexes, Paris: CNRS, p. 227-244.

TAMPEP (2009) Sex Work in Europe. A mapping of the prostitution scene in 25 European countries. in L. Brussa Tampep 8 Programme, Amsterdam: TAMPEP International Foundation http://tampep.eu/documents/TAMPEP\%202009\%20European\%20Mapping\%20Report.pdf.

VANWESENBEECK, I. (2005) 'Burnout amongst female indoor sex work', Archives of Sexual Behaviour, Vol. 34, Issue 6, p. 627-639. [doi:10.1007/s10508-005-7912-y]

VIRNO, P. , HARDT, M. (eds.) (1996) Radical thought in Italy: A potential politics. Minneapolis: University of Minnesota Press.

WEST, J. (2000) 'Prostitution: Collectives and the politics of regulation', Gender, Work and Organization, Vol. 7, Issue 2, p.106-118. [doi:10.1111/1468-0432.00098]

WITZ, A. (1990) 'Patriarchy and Professions: The Gendered Politics of Occupational Closure' Sociology, Vol. 24 , Issue 4, p. 675-690.

WOLKOWITZ, C., COHEN, R. L., SANDERS, T. and HARDY, K. (Eds.) (2012) Body/sex/work: Intimate, 
